\title{
Development of a Nanoformulation for Oral Protein Administration: Characterization and Preclinical Orofacial Antinociceptive Effect
}

\section{Marina de Barros Mamede Vidal Damasceno}

University of Fortaleza: Universidade de Fortaleza

\section{Sacha Aubrey Alves Rodrigues Santos}

University of Fortaleza: Universidade de Fortaleza

João Ronielly Campêlo Araújo

University of Fortaleza: Universidade de Fortaleza

\section{Lana Karine Vasconcelos Barroso}

University of Fortaleza: Universidade de Fortaleza

\section{Samara Casemiro Benevides}

University of Fortaleza: Universidade de Fortaleza

\section{Francisco Ernani Alves Magalhães}

State University of Ceara: Universidade Estadual do Ceara

Kaio César Simiano Tavares

University of Fortaleza: Universidade de Fortaleza

\section{Renato de Azevedo Moreira}

University of Fortaleza: Universidade de Fortaleza

Ana Cristina de Oliveira Monteiro-Moreira

University of Fortaleza: Universidade de Fortaleza

Angelo Roncalli Alves e Silva

University of Fortaleza: Universidade de Fortaleza

Adriana Rolim Campos ( $\nabla$ adrirolim@unifor.br)

Universidade de Fortaleza https://orcid.org/0000-0002-7355-9310

\section{Research Article}

Keywords: Frutalin, orofacial nociception, TRPV1, oral route, nanobiotechnology

Posted Date: January 25th, 2022

DOI: https://doi.org/10.21203/rs.3.rs-972048/v1 
License: (c) (i) This work is licensed under a Creative Commons Attribution 4.0 International License. Read Full License 


\section{Abstract}

Nanoencapsulation is a valid alternative for the oral administration of peptide drugs and proteins, as nanoparticles protect them from proteolytic degradation in the gastrointestinal tract and promote the absorption of these macromolecules. The orofacial antinociceptive effect of frutalin (FTL), through the intraperitoneal route, has already been proven. This study aimed to develop, characterize, and evaluate the orofacial antinociceptive activity of an oral formulation containing FTL in acute and neuropathic preclinical tests. The analyzed sample did not show any cytotoxicity; $52.2 \%$ of the FTL was encapsulated, the size of the nanocapsules was less than $200 \mathrm{~nm}$, the polydispersion was 0.361 and the zeta potential was -5.87 millivolts. Nanoencapsulated FTL administered by oral route had an orofacial antinociceptive effect in acute and neuropathic rodent models. The antinociceptive effect of FTL was prevented by ruthenium red, but not by camphor. FTL reduced Trpv1 gene expression. FTL promotes orofacial antinociception probably due to the antagonism of TRPV1 channels and the nanoformulation represents an effective method of administering this protein orally.

\section{Introduction}

Nanoencapsulation is a valid alternative for oral administration of peptide drugs and proteins, as nanoparticles protect them from proteolytic degradation in the gastrointestinal tract and promote the absorption of these macromolecules. Nanoparticles made up of biodegradable natural polymers have increasingly attracted the attention of researchers (Allemann et al. 1998). Chitosan is an example of these polymers, as it is biocompatible with the encapsulation of several drugs (Tsai et al. 2011; Tiyboonchai, et al. 2003; Silva et al. 2006).

Orofacial pain is an extremely prevalent and debilitating condition that affects more than a quarter of the population, inducing a significant reduction in the quality of life, which can lead to patient disability. These pains arise from the structures innervated by the trigeminal system (head, face, masticatory muscles, temporomandibular joint and associated structures) (Hargreaves 2011).

Trigeminal neuropathic pain can arise from injuries resulting from dental procedures, infections, neoplasms or certain dysfunctions of the peripheral and/or central nervous system. Neurovascular disorders, such as primary headaches, can present as chronic orofacial pain, and may occur in the second or third division of the trigeminal nerve (Romero-Reyes et al. 2014; Shueb et al. 2015).

An ideal multidisciplinary approach to control and/or treat this disorder includes pharmacological and non-pharmacological modalities, therefore comprising a clinical challenge, precisely because of its multifactorial origin (Damasceno et al. 2016; Romero-Reyes et al. 2014). Frutalin (FTL), a vegetable lectin isolated from the seeds of Artocarpus altilis $L$, is a tetrameric glycoprotein, an alpha-D galactose ligand (Jagtap et al. 2010; Moreira et al. 1998). Recently, our group confirmed the orofacial antinociceptive effect of this macromolecule in acute and neuropathic models (Damasceno et al. 2016). However, there 
are obstacles that prevent its oral administration, such as its high molecular weight and the fact that it is degraded in the stomach (Zhou 1994; Tiyboonchai et al. 2003).

The objective of this study is to develop nanocapsules containing FTL and evaluate its orofacial antinociceptive effect in rodents.

\section{Materials And Methods}

\section{Obtaining of frutalin}

Frutalin was obtained from Artocarpus incisa seeds as previously reported (Moreira et al. 1998). The sample purity was assessed by SDS-PAGE according to Laemmli (1970).

\section{Chitosan treatment}

The chitosan treatment process $\left(\mathrm{QT}\right.$; Polymar $\left.{ }^{\circledR}\right)$ was carried out aiming at removing calcium carbonate and phosphate residues. Initially, $2 \mathrm{~g}$ of QT were diluted in $198 \mathrm{~mL}$ of $0.1 \%$ aqueous acetic acid solution, under constant stirring until complete solubilization (overnight - $24 \mathrm{~h}$ ). Then, when the QT solution was completely dissolved, it was filtered using a Buchner funnel, to separate undissolved impurities, and, subsequently, 4 drops of a $1 \mathrm{M} \mathrm{NH} 4 \mathrm{OH}$ solution were added until the precipitation of all the dissolved QT. Approximately 5 washes of the precipitate were made using filter paper, initially with distilled water and later with methanol, for total removal of impurities and better drying conditions. This precipitate was placed in the oven at a temperature of $40^{\circ} \mathrm{C}$ for $24 \mathrm{~h}$ and then it was pulverized using a mortar and pestle (Signini et al. 1998).

\section{Preparation of the nanocapsules}

The nanocapsules (NC) were prepared according to the method described by Soares et al. (2012). Two solutions were prepared: $1: 0.015 \mathrm{~g}$ of QT, $26.25 \mu \mathrm{L}$ of acetic acid and $15 \mathrm{~mL}$ of distilled water, and 2: $0.006 \mathrm{~g}$ of tripolyphosphate (TPP), $0.0011 \mathrm{~g}$ of FTL and $5.5 \mathrm{~mL}$ of distilled water, which were placed on plates and underwent agitation until they were completely solubilized. Then, 3 drops of a $1 \mathrm{M} \mathrm{NaOH}$ solution were added for $\mathrm{pH}$ adjustment, which was equal to 9. Subsequently, solution 2 was dripped into solution 1, while observing the formation of turbidity in the solution, which is indicative of NC formation; this newly formed stable colloidal system should have $\mathrm{pH}=7$.

\section{Encapsulation efficiency}

FTL cross-linked chitosan NC were centrifuged at 20,000 g at 4 oC for 30 min and the supernatant was removed and submitted to protein analysis using the BCA Protein Assay Kit through the bicinchoninic acid method (Fernandes-Pedrosa et al., 2002). The assays were performed in triplicate and the FTL encapsulation efficiency (EE \%) was calculated using Eq.: EE\% = (total protein amount - free protein amount in the supernatant) / (total protein amount) x 100 (Gan et al. 2005). 


\section{Size and zeta potential}

\section{Analysis of Particle size}

The hydrodynamic diameter of the colloidal particles was determined using dynamic light scattering (DLS), also known as photon correlation spectroscopy. NC samples containing FTL or not were prepared with ultrapure water, using a dilution factor of 1:100 for each formulation. The readings were performed using a set of standardized acrylic cuvettes provided together with the equipment. For each measurement, a statistical $n$ equal to 3 was used. In addition to particle size distribution, the polydispersity index (PDI) was also recorded (Sawtarie et al. 2017).

\section{Determination of zeta potential}

The zeta potential of the colloidal particles was determined following a similar experimental protocol to that described in the previous item for determining the hydrodynamic diameter. However, the equipment was adjusted to a module for obtaining membrane potential, using a special cuvette adapted with external electrodes to measure the voltage $(\mathrm{mV})$. All measurements were performed with a statistical $\mathrm{n}$ equal to 3, with the results being evaluated by an algorithmic test using Malvern software, to approve and adjust them within the reliability criteria (Sawtarie et al. 2017).

\section{Scanning electron microscopy}

The assembly was carried out (by placing the adhesive tape and disposing of $30 \mu \mathrm{L}$ of the nanocapsule in stubs), and then this sample was placed in a desiccator with silica gel for $48 \mathrm{~h}$. Subsequently, a layer containing $20 \mathrm{~nm}$ of gold was applied and, afterwards, this sample was taken to the metallizer for 10 min. The structural analysis of the NC was performed in the Central Analytical laboratory of the Federal University of Ceará (UFC) using a scanning electron microscope (Quanta 450-FEG (FEI)). A descriptive analysis of the nanocapsules was performed through photomicrographs (Youm et al. 2011).

\section{Cytotoxicity to Vero cells}

The tested groups were as follows: control (vehicle), $0.5 \mathrm{mg} / \mathrm{mL}$ FTL, NC without FTL and NC containing FTL. These groups were submitted to the test of specific cytotoxicity to Vero cells (African green monkey kidney), using the MTT colorimetric method (Mosmann, 1983). The cells were incubated (1000- 62.5 $\mu \mathrm{g} / \mathrm{mL}$ ) with vehicle, $\mathrm{FTL}, \mathrm{NC}$ without $\mathrm{FTL}$ or $\mathrm{NC}$ containing $\mathrm{FTL}$, and the percentage of cell viability was calculated. The concentration reducing viability to $50 \%$ compared to cell control (CC50) was obtained by analyzing the non-linear regression of the concentration-effect curve. The cytotoxicity potential (CTP) of the sample was classified according to Fadeyi (2013) into (a) Toxic (CC50 $\leq 30 \mu \mathrm{g} / \mathrm{mL}$ ), or b) Nontoxic $(\mathrm{CC} 50>30 \mu \mathrm{g} / \mathrm{mL})$.

\section{Antinociceptive effect}

\section{Animals}


Swiss albino mice (20 - $30 \mathrm{~g})$ and Wistar rats $(250$ - $300 \mathrm{~g})$ obtained from the Núcleo de Biologia Experimental animal facility of the University of Fortaleza were used. They were housed (IVC cages, Techniplast $\left.{ }^{\circledR}\right)$ under environmentally controlled conditions $\left(22^{\circ} \mathrm{C}, 12 \mathrm{~h}\right.$ light-dark cycle), with free access to a standard pellet diet (Purina, São Paulo, Brazil) and water. The experimental protocols were in accordance with the ethical guidelines of the Brazilian National Council for the Control of Animal Experimentation (Animal Ethics Committee of the University of Fortaleza, \#021/2016).

\section{Treatments}

Animals ( $n=6 /$ group) were divided into the following groups:

$1-0.9 \% \mathrm{NaCl}(0.1 \mathrm{~mL} / 10 \mathrm{~g}$; intraperitoneal i.p.; vehicle control);

2 - NC containing FTL (0.1 mL/10 g; per os - p.o.);

3 - NC without FTL (0.1 mL/10 g; p.o.);

4 - $0.5 \mathrm{mg} / \mathrm{Kg}$ FTL (0.1 mL/10 g; p.o.);

5 - $0.5 \mathrm{mg} / \mathrm{Kg}$ FTL (0.1 mL/10 g; i.p.);

6 - Naive (no treatment).

\section{Capsaicin-induced orofacial nociception}

Capsaicin $(2.5 \mu \mathrm{g}, 20 \mu \mathrm{L})$ dissolved in ethanol, PBS and distilled water (1:1:8) was injected into the perinasal area of the mice, $30 \mathrm{~min}$ (p.o.) or $1 \mathrm{~h}$ (i.p.) after the treatments (see above). The number of times the face-rubbing behavior occurred was observed for 10 to $20 \mathrm{~min}$ after capsaicin administration (Pelisser et al. 2002; Melo Junior et al. 2017).

\section{Eye wiping test}

$\mathrm{NaCl}(5 \mathrm{M}, 20 \mu \mathrm{L})$ was applied locally on the surface of the right cornea of mice using a fine tip dropper, $30 \mathrm{~min}$ (p.o.) or $1 \mathrm{~h}$ (i.p.) after the treatments (see above). The number of times the eye-wiping behavior was performed with the ipsilateral forepaw was counted for a period of $30 \mathrm{~s}$ (Farazifard et al. 2005).

\section{Temporomandibular joint (TMJ) formalin test}

Rats were first placed individually in a test chamber (30 x $30 \times 30 \mathrm{~cm}$ glass-chamber) for a 30 -min habituation period to minimize stress. Formalin $(2 \%)$ or its vehicle $(0.9 \% \mathrm{NaCl})$ was injected into the left TMJ $(50 \mu \mathrm{L})$ using a Hamilton syringe connected to a 30-gauge needle, $30 \mathrm{~min}$ (p.o.) or $1 \mathrm{~h}$ (i.p.) after the treatments (see above) (Souza et al. 2019; Zhou et al. 1999).

Following the TMJ injection, after recovering from the anesthesia, each animal was returned to the test chamber for the counting of two types of nociceptive behavior: rubbing the orofacial region 
asymmetrically with the ipsilateral fore or hind paw and flinching the head (intermittently and reflexively shaking of the head). The rats' behavior following the formalin injection was evaluated in 12 blocks of 3 min (Gameiro et al. 2005; (Roveroni et al. 2001).

For each block of $3 \mathrm{~min}$, the orofacial rubbing behavior was quantified using a chronometer that recorded the number of times the animal rubbed the orofacial region, and the flinching behavior was quantified according to its occurrence (Roveroni et al. 2001).

\section{Infraorbital nerve transection}

The left infraorbital nerve (ION) of the mice was exposed at its entry zone into the infraorbital foramen, through an intra-oral incision $(2 \mathrm{~mm})$ made in the oral mucosa of the left frontal-lateral maxillary vestibulum while anesthetized (100 mg/kg ketamine and $10 \mathrm{mg} / \mathrm{kg}$ xylazine; i.p.). The ION was lifted from the maxillary bone and cut (IONX) without damaging the other nerves and vessels in the vicinity. The animals were returned to their home cages and fed with mash and chow. A sham or false operation group, in which only one incision was made without rupture of the trigeminal ganglion, was included. The animals were monitored daily during the postoperative period.

\section{Assessing Mechanical Sensitivity}

The animals were acclimated, trained, and tested for facial mechanical sensitivity three days prior to nerve transection (baseline) and on postoperative days 1, 3, 5, 7, 10, 14 and 21. Treatments (see above) were administered 30 (p.o.) or 60 (i.p.) min before each postoperative test. Mechanical sensitivity of the whisker pad skin was assessed using von Frey hairs. The head-withdrawal threshold to mechanical stimulation of the whisker pad skin was defined as the minimum pressure needed to evoke an escape more than 3 times for 5 stimuli (Saito et al. 2008).

\section{Evaluation of the participation of TRPV1 and TRPA1 channels in the FTL orofacial antinociceptive mechanism of action}

\section{Capsaicin-induced orofacial nociception}

Mice ( $\mathrm{n}=6 /$ group) were treated $(0.1 \mathrm{~mL} / 10 \mathrm{~g})$ with FTL $(0.5 \mathrm{mg} / \mathrm{kg}$; i.p.), ruthenium red (TRPV1 antagonist; $3 \mathrm{mg} / \mathrm{kg}$; subcutaneous) or vehicle ( $0.9 \% \mathrm{NaCl}$; i.p.). A fourth group $(\mathrm{n}=6)$ received ruthenium red 15 min before the administration of FTL. Capsaicin (TRPV1 agonist) was injected into the perinasal area of the mice, $30 \mathrm{~min}$ after treatments and the number of times the face-rubbing behavior occurred was observed during 10 to 20 min after capsaicin administration. The trigeminal ganglion was removed and stored at $-80^{\circ} \mathrm{C}$ for further analysis of the gene expression of the Trpv1 channels.

\section{RT-PCR}

Total RNA from trigeminal ganglion samples was extracted using the TRIzol ${ }^{\odot}$ Reagent (Thermo Scientific, USA) accordingly to the manufacturer's instructions. Samples were treated with DNase I (Thermo 
Scientific, USA) and reverse transcribed using the SuperScript III enzyme (Thermo Scientific, USA) and oligo(dT) primers. Specific primers for the Trpv1 gene (Trpv1-F 5' CCCGGAAGACAGATAGCCTGA 3' and Trpv1-R 5' TTCAATGGCAATGTGTAATGCTG 3') were used for amplifications (Primer Bank, Harvard Medical School). The Gapdh gene was chosen as endogenous control, and specific primers (Gapdh-F 5' GTCGTGGAGTCTACTGGTGTC 3' and Gapdh-R 5' CTGTGGTCATGAGCCCTTCC 3') were designed using the Primer BLAST tool (https://www.ncbi.nlm.nih.gov/tools/primer-blast). Amplifications were conducted in a StepOne Plus Thermocycler (Applied Biosystems) using $0.2 \mu \mathrm{M}$ of each primer, 1 X Power SYBR Green PCR Master Mix (Thermo Scientific, Cat. n. 4368577) and $1 \mu \mathrm{L}$ of cDNA. Reactions were incubated at $95^{\circ} \mathrm{C}$ for $10 \mathrm{~min}$, followed by 45 cycles of $95^{\circ} \mathrm{C}$ for $30 \mathrm{~s}, 58^{\circ} \mathrm{C}$ for $30 \mathrm{~s}$ and $72^{\circ} \mathrm{C}$ for $30 \mathrm{~s}$ followed by a melting curve. Non-template controls were performed for each primer. Data were normalized using the 2$\Delta \Delta C T$ methodology (Livak and Schmittgen 2001).

\section{Cinnamaldehyde-induced orofacial nociception}

Mice ( $\mathrm{n}=6 /$ group) were treated $(0.1 \mathrm{~mL} / 10 \mathrm{~g})$ with FTL ( $0.5 \mathrm{mg} / \mathrm{kg}$; i.p.), camphor (TRPA1 antagonist; 7,6 $\mathrm{mg} / \mathrm{kg}$; s.c; subcutaneous) or vehicle $(0.9 \% \mathrm{NaCl}$; i.p.). A fourth group $(\mathrm{n}=6)$ received camphor $15 \mathrm{~min}$ before the administration of FTL. Cinnamaldehyde (TRPA1 agonist; $13.2 \mu \mathrm{g} / \mathrm{vibrissa}$ ) was injected into the perinasal area of the mice, $30 \mathrm{~min}$ after the treatments and the number of times the face-rubbing behavior occurred was observed for 0 to 5 min after cinnamaldehyde administration (Nomura et al. 2013).

\section{Statistical analysis}

The results are presented as the mean \pm S.E.M. of 6 animals per group. Statistical analysis was carried out using one-way or two-way analysis of variance (ANOVA), followed by Tukey or Bonferroni posthoc tests for multiple comparisons. P-values less than $0.05(p<0.05)$ were considered as indicative of statistical significance.

\section{Results}

\section{Scanning electron microscopy}

The average size of the FTL-containing nanocapsules was $119.50 \pm 2.35 \mathrm{~nm}$. The blank formulation showed an average zeta potential of - 5.87 millivolts. The process yielded particles in the nanometric range with a low polydispersion index (PDI), approximately equal to 0.361 , indicating a monodispersed population and the formation of a unimodal distribution. The SEM results (Fig. 1) resulted in images with a rounded shape, and a low variation in size distribution (152.00 to $182.50 \mathrm{~nm}$ ) was observed.

\section{Encapsulation efficiency}

An encapsulation of $52.2 \%$ of FTL was attained (data not shown).

Antinociceptive effect of frutalin and the nanocapsule containing FTL 
As shown in Table 1, nanocapsules containing FTL resulted in a reduction in face-rubbing behaviors induced by capsaicin ( $\star \star \star \star p p<0.0001 v s$. control), decreased the number of eye-wiping behaviors induced

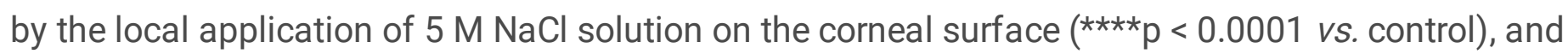
reduced the orofacial rubbing and head flinching behaviors in the TMJ formalin test $(* \star \star \star p<0.0001 v s$. control).

Table 1

Effect of frutalin and the nanocapsule containing FTL.

\begin{tabular}{|c|c|c|c|c|}
\hline \multirow[t]{2}{*}{ Groups } & \multirow[t]{2}{*}{ Dose (mg/kg) } & \multicolumn{3}{|l|}{ Behavior (s) } \\
\hline & & Capsaicin & $5 \mathrm{M} \mathrm{NaCl}$ & Formalin \\
\hline Control & - & $24.170 \pm 1.887$ & $13.170 \pm 1.302$ & $131.000 \pm 23.740$ \\
\hline FTL i.p. & 0.5 & $3.167 \pm 0.872^{\star \star \star \star}$ & 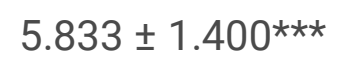 & $30.330 \pm 4.063^{\star * \star}$ \\
\hline FTL p.o. & 0.5 & $17.330 \pm 4.333$ & $12.330 \pm 1.308$ & $1143.200 \pm 24.430$ \\
\hline $\mathrm{NC} c / \mathrm{FTL}$ & 0.5 & $2.833 \pm 0.872^{\star \star \star \star}$ & 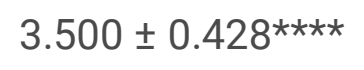 & $16.000 \pm 3.856^{\star \star \star \star *}$ \\
\hline $\mathrm{NC} w / F T L$ & - & $13.830 \pm 3.321^{\star}$ & $8.167 \pm 1.078^{\star \star}$ & $124.200 \pm 14.710$ \\
\hline Naive & - & $1.000 \pm 0.516^{\star \star \star \star}$ & 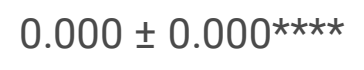 & $5.833 \pm 0.792^{\star \star \star \star}$ \\
\hline
\end{tabular}

Infraorbital nerve transection produced sustained changes in sensory processing, resulting in transient hypersensitivity to mechanical stimulation in the area innervated by the injured ION (Fig. 2). The mice treated with FTL $(0.5 \mathrm{mg} / \mathrm{kg})$, showed a significant decrease in the face-rubbing behavior and less thermal hypersensitivity up to the tenth postoperative day, while the group that was treated with nanocapsules containing FTL showed an even better response, which lasted up to the last day of the experiment ( 21 days postoperatively). There was no weight variation of the animals during the experiment.

\section{Participation of TRPV1 and TRPA1 channels}

The orofacial antinociceptive effect of frutalin was prevented by the pretreatment with ruthenium red (non-competitive TRPV1 channel antagonist, Fig. 3A), but not by camphor (Fig. 3B). Levels of Trpv1 gene specific transcripts were reduced almost nine-fold $(p<0.05)$ in the frutalin-treated group when compared with the control (Fig. 3).

\section{Gene expression}


In the analysis of the Trpv1 gene expression in the trigeminal ganglion of mice stimulated with capsaicin, we showed a reduced expression of the Trpv1 channels in the FTL-treated group compared to the control group (Fig. 4).

\section{Cytotoxicity to Vero cells}

Nanocapsules containing FTL were not toxic to Vero cells (data not shown). The average size by DLS was different when compared to SEM.

\section{Discussion}

Nanocapsules containing frutalin (FTL) were developed using the ionic gelation technique. The solution turbidity, as well as its $\mathrm{pH}(=7)$, suggest that cross-linking occurred, with the formation of a stable colloidal system.

Size determination of nanoparticle suspensions is not straightforward. These systems have complex particle size distributions and are broad polydisperse ones (Braun et al. 2011; Gaumet et al. 2008). The PDI does not seem to be exceptionally low; this parameter is a dimensionless measurement of particle size distribution broadness, which ranges from 0 to 1 . According to this approach, the PDI is calculated from the cumulative analysis using the equipment software. Values $>0.7$ indicate a broad distribution of particle sizes, while a PDI > 1 indicates that the sample may not be suitable for DLS measurements (Streck et al. 2018). However, these nanoparticles show antinociceptive effect with $50 \%$ of drug loading and size and particle size distributions was not influenced by that effect.

The orofacial antinociceptive effect of frutalin (FTL) has been previously demonstrated by our group and this effect seems to be mediated by the modulation of TRPV1 channels (Damasceno et al. 2016; Barros et al. 2017). However, FTL in a solution does not become active when administered orally. In this study, we describe its orofacial antinociceptive effect after oral administration of its nanoencapsulated form. The attained effect was more effective and longer lasting when compared to that of non-encapsulated lectin, when administered intraperitoneally (i.p.).

The average size $(119 \mathrm{~nm})$ certifies that the obtained nanocapsules (NC) are within the defined range for nanosystems. Another important aspect, associated with this type of analysis is the polydispersion index (PDI), which indicates the uniformity of the diameters of the suspended particles. High PDI values are related to a large variation in particle size, whereas low values suggest a smaller variation. The PDI of the nanocapsules obtained in this study allows the consideration of the uniformity of sizes, with this aspect being fundamental to guarantee uniformity in the concentration of the encapsulated substance, characterizing it as a homogeneous dispersion (Moretton et al. 2013).

The properties of the solution can be influenced by independent factors, changing the zeta potential of the NC. The average size obtained in this study is similar to that observed by Soumya et al. (2009) and Antoniou et al. (2015). The value considered ideal for the zeta potential is $\pm 30 \mathrm{mV}$, according to the 
measurement of the particle surface charge. This value is considered ideal, as it allows the contribution of this potential to the system stability, preventing the aggregation of particles (Fan et al. 2012). The zeta potential showed a negative surface charge, corroborating the study by Carneiro da Cunha et al. (2011).

The variation observed regarding the value of the NC zeta potential, with and without $F T L$, justifies the influence of the "chitosan-FTL" system in an aqueous solution, providing a characteristic profile of this formulation. The results of scanning electron microscopy (SEM) are close to those found in photo correlation spectroscopy, when the values were plotted according to the statistical size distribution (data not shown), with sizes between 150 to $190 \mathrm{~nm}$ being observed. During image treatment, it was verified that the particle sizes ranged from 152.0 to $182.5 \mathrm{~nm}$, thus showing a low size variation and, therefore, justifying the low polydispersity value observed in the photo correlation spectroscopy. The intraperitoneal administration of FTL decreased the number of times of orofacial rubbing induced by capsaicin, the number of eye-wiping behaviors induced by hypertonic saline, and the nociceptive behavior induced by formalin injection in the temporomandibular (TMJ) region, as shown by Damasceno et al. 2016. Here, as expected, FTL administered by gavage showed no antinociceptive effect. However, when FTL was nanoencapsulated, and administered by gavage, the orofacial antinociceptive effect was similar to the intraperitoneal administration of non-encapsulated FTL in all nociceptive tests.

FTL (0.5 mg/kg; i.p.) decreased thermal (Damasceno et al. 2016) and mechanical hypersensitivity on postoperative days 3 to 10 after infraorbital nerve transection. In this study, nanoencapsulated FTL prolonged the antinociceptive effect up to the 21 st postoperative day.

It was observed that the lectin effect was abolished by pretreatment with the TRPV1 channel antagonist (ruthenium red), but not by the TRPA1 channel antagonist (camphor), suggesting a specific FTL action on the vanilloid channels. In the analysis of the expression of the Trpv1 gene in the trigeminal ganglion of mice stimulated with capsaicin, a reduced expression of the Trpv1 channels was demonstrated in the FTL-treated group, when compared to the control group. These findings suggest that the orofacial antinociceptive effect of FTL may be related to TRPV1 channel antagonism.

Based on the molecular docking study between FTL and TRPV1 and TRPA1 channels, FTL strongly interacts with TRPV1 (Damasceno et al. 2016) and has a weak interaction with TRPA1 (Barros et al. 2017). These results corroborate the in vivo and in vitro findings, supporting the concept that this protein is in fact an antagonist of the vanilloid channels.

\section{Conclusion}

Frutalin promotes orofacial antinociception, probably due to the antagonism of TRPV1 channels. The nanoformulation developed through the ionic gelation technique was adequate, showing no cytotoxicity and therefore representing an effective way of administering this protein orally, enabling its use to control and or treat acute and neuropathic orofacial pain. 


\section{Declarations}

\section{Declaration of competing interests}

The authors declare no conflicts of interest.

\section{Funding}

The present study was supported by CAPES (\#053/2014), CNPq (\#302319/2019-0), FUNCAP (\#BMD0124-00063.01.00/17) and Edson Queiroz Foundation (\#49/2019).

\section{Acknowledgements}

Not applicable.

\section{CRediT authorship contribution statement}

Marina de Barros Mamede Vidal Damasceno: Conceptualization, Investigation. Writing - original draft preparation. Sacha Aubrey Alves Rodrigues Santosa: Investigation. João Ronielly Campêlo Araújo: Investigation. Lana Karine Vasconcelos Barroso: Investigation. Samara Casemiro Benevides: Investigation. Francisco Ernani Alves Magalhães: Investigation. Kaio César Simiano Tavares: Investigation. Renato de Azevedo Moreira: Investigation. Ana Cristina de Oliveira MonteiroMoreira: Investigation. Angelo Roncalli Alves e Silva: Conceptualization, Methodology, Writing - original draft preparation, editing. Adriana Rolim Campos: Conceptualization, Methodology, Writing - original draft preparation, editing.

\section{References}

1. Allemann E, Leroux J, Gurny R (1998) Polymeric nano-and microparticles for the oral delivery of peptides and peptidomimetics. Adv Drug Deliv Rev 24:171-189. https://doi.org/10.1016/s0169409x(98)00039-8

2. Antoniou J, Liu F, Majeed H, Zhong F (2015) Characterization of tara gum edible films incorporated with bulk chitosan and chitosan nanoparticles: a comparative study. Food Hydrocoll 44:309-319. https://doi.org/10.1016/j.foodhyd.2014.09.023

3. Barros ARC, Damasceno MBMV, Santos SAAR, Melo-Junior JMA, Magalhães FEA, Vieira-Neto AE, Moreira RA, Monteiro-Moreira ACO (2017) TRPV1 mediates the orofacial antinociceptive effect of frutalin: in vivo and in silico Studies. FASEB J 31(1):8126. https://doi.org/10.1096/fasebj.31.1_supplement.812.6

4. Braun A, Couteau O, Franks K, Kestens V, Roebben G, Lamberty A, Linsinger TPJ (2011) Validation of dynamic light scattering and centrifugal liquid sedimentation methods for nanoparticle characterization. Adv Powder Technol 22:766-770. https://doi.org/10.1016/j.apt.2010.11.001 
5. Carneiro-da-Cunha MG, Cerqueira MA, Souza BWS, Teixeira JA, Vicente AA (2011) Influence of concentration, ionic strength and $\mathrm{pH}$ on zeta potential and mean hydrodynamic diameter of edible polysaccharide solutions envisaged for multinanolayered films production. Carbohydr Polym 85:522-552. https://doi.org/10.1016/j.carbpol.2011.03.001

6. Damasceno MBMV, Melo Junior JMA, Santos SAAR, Melo LTM, Leite LHI, Vieira-Neto AE, Moreira RA, Monteiro-Moreira ACO, Campos AR (2016) Frutalin reduces acute and neuropathic nociceptive behaviours in rodent models of orofacial pain. Chem Biol Interact 256:9-15. https://doi.org/10.1016/j.cbi.2016.06.016

7. Fadeyi SA, Fadeyi 00, Adejumos AA, Okoro C, Myles EL (2013) In vitro anticancer screening of 24 locally used Nigerian medicinal plants. BMC Complement Altern Med 13:79-87. https://doi.org/10.1186/1472-6882-13-79

8. Fan W, Yan W, Xu Z, Ni H (2012) Formation mechanism of mono disperse, low molecular weight chitosan nanoparticles by ionic gelation technique. Colloids Surf B Biointerfaces 90:21-27. https://doi.org/10.1016/j.colsurfb.2011.09.042

9. Farazifard R, Safarpour F, Sheibani V, Javan M (2005) Eye wiping test: a sensitive animal model for acute trigeminal pain studies. Brain Res Protoc 16:44-49. https://doi.org/10.1016/j.brainresprot.2005.10.003

10. Fernandes-Pedrosa MF, Azevedo ILMJ, Gonçalves-de-Andrade RM, Van Den Berg CW, Ramos CRR, Ho PL, Tambourgi DV (2002) Molecular cloning and expression. Of a functional dermonecrotic and haemolytic fator from Loxosceles laeta venon. Biochem Biophys Res Commun 298(5):638-645. https://doi.org/10.1016/S0006-291X(02)02521-4

11. Gameiro GH, Andrade AS, de Castro M, Pereira LF, Tambeli CH, Veiga MCFA (2005) The effects of restraint stress on nociceptive responses induced by formalin injected in rats TMJ. Pharmacol Biochem Behav 82(2):338-344. https://doi.org/10.1016/j.pbb.2005.09.003

12. Gan $Q$, Wang T, Cochrane $C$, McCarron $P$ (2005) Modulation of surface charge, particle size and morphological properties of chitosan-TPP nanoparticles intended for gene delivery. Colloids Surf B Biointerfaces 44:65-73. https://doi.org/10.1016/j.colsurfb.2005.06.001

13. Gaumet M, Vargas A, Gurny R, Delie F (2008) Nanoparticles for drug delivery: The need for precision in reporting particle size parameters. Eur J Pharm Biopharm 69:1-9. https://doi.org/10.1016/j.ejpb.2007.08.001

14. Hargreaves KM (2011) HHS Public Access, Congress Orofacial Pain (3 Suppl) 152. 25-32. https://dx.doi.org/10.1016\%2Fj.pain.2010.12.024

15. Jagtap UB, Bapat VA (2010) Artocarpus: A review of its traditional uses, phytochemistry and pharmacology. J Ethanopharmacol 129:2, 142-166. https://doi.org/10.1016/j.jep.2010.03.031

16. Laemmli UK (1970) Cleavage of structural proteins during the assembly of the head of bacteriophage T4. Nature 227(5259):68085. https://doi.org/10.1038/227680a0

17. Livak KJ, Schmittgen TD (2001) Analysis of relative gene expression data using real-time quantitative PCR and the 2 (-Delta Delta C(T)) Method. Methods 25:402-408. 
https://doi.org/10.1006/meth.2001.1262

18. Melo Júnior JMA, Damasceno MBMV, Santos SAAR, Barbosa TM, Araújo JRC, Vieira-Neto AE, Wong DV, Lima-Júnior RC, Campos AR (2017) Acute and neuropathic orofacial antinociceptive effect of eucalyptol. Inflammopharmacology 25(2):247-254. doi: 10.1007/s10787-017-0324-5

19. Moreira RA, Castelo-Branco CC, Monteiro-Moreira ACO, Tavares RO, Beltramini LM (1998) Isolation and partial characterization of a lectin from Artocarpus incisa L. Seeds Phytochemistry 47:11831188. https://doi.org/10.1016/s0031-9422(97)00753-x

20. Moretton MA, Chiappetta DA, Andrade F, das Neves J, Ferreira D, Sarmento B, Sosnik A (2013) Hydrolyzed galactomannan-modified nanoparticles and flower-like polymeric micelles for the active targeting of rifampicin to macrophages. J Biomed Nanotechnol 9:1-12.

https://doi.org/10.1166/jbn.2013.1600

21. Mosmann T (1983) Rapid colorimetric assay for cellular growth and survival: application to proliferation and cytotoxicity assays. J Immunol Methods 65:55-63. https://doi.org/10.1016/00221759(83)90303-4

22. Nomura ECO, Rodrigues MRA, da Silva CF, Hamm LA, Nascimento AM, de Souza LM, Cipriani TR, Baggio CH, Werner MFP (2013) Antinociceptive effects of ethanolic extract from the flowers of Acmella oleracea (L.) R.K. Jansen in mice. J Ethnopharmacol 50(2):583-589. https://doi.org/10.1016/j.jep.2013.09.007

23. Pelisser T, Pajot J, Dallel R (2002) The orofacial capsaicin test in rats: effects of different capsaicin concentrations and morphine. Pain 96:81-87. https://doi.org/10.1016/s0304-3959(01)00432-8

24. Romero-Reyes M, Uyanik JM (2014) Orofacial pain management: current perspectives. J Pain Res 7:99-115. https://dx.doi.org/10.2147\%2FJPR.S37593

25. Roveroni RC, Parada CA, Veiga MCFA, Tambeli CH (2001) Development of a behavioral model of TMJ pain in rats: the formalin test. Pain 94:185-191. https://doi.org/10.1016/s03043959(01)00357-8

26. Saito K, Hitomi S, Suzuki I, Masuda Y, Kitagawa J, Tsuboi Y, Kondo M, Sessle BJ, Iwata K (2008) Modulation of trigeminal spinal subnucleus caudalis neuronal activity following regeneration of transected inferior alveolar nerve in rats. J Neurophysiol 99:2251-2263. https://doi.org/10.1152/jn.00794.2007

27. Sarciaux JM, Acar L, Sado PA (1995) Using microemulsion formulations for oral drug delivery of therapeutic peptides. Int J Pharm 120:127-136. https://doi.org/10.1016/0378-5173(94)00386-J

28. Sawtarie N, Cai Y, Lapitsky Y (2017) Preparation of chitosan/tripolyphosphate nanoparticles with highly tunable size and low polydispersity. Colloids Surf B Biointerfaces 1:157, 110-117. https://doi.org/10.1016/j.colsurfb.2017.05.055

29. Shueb SS, Nixdorf DR, John MT, Alonso BF, Durham J (2015) What is the impact of acute and chronic orofacial pain on quality of life? J Dent 43:1203-1210. https://doi.org/10.1016/j.jdent.2015.06.001 
30. Signini R, Sérgio F, Campana SP (1998) Purificação e caracterização de quitosana comercial. Polímeros: Ciênc Tecnol 8:63-68. http://dx.doi.org/10.1590/S0104-14281998000400009

31. Silva HSRC, Santos KSCR, Ferreira El (2006) Quitosana: Derivados hidrossolúveis, aplicações farmacêuticas e avanços. Quim Nova 29(4):776-785. https://doi.org/10.1590/S010040422006000400026

32. Soares KSR, Fonseca JLC, Bitencourt MAO, Santos KSCR, Silva-Junior AA, Fernandes-Pedrosa MF (2012) Serum production against Tityus serrulatus scorpion venom using cross-linked chitosan nanoparticles as immunoadjuvant. Toxicon 60:1349-1354. https://doi.org/10.1016/j.toxicon.2012.09.010

33. Soumya RS, Ghosh S, Abraham ET (2009) Preparation and characterization of guar gum nanoparticles. Int J Biol Macromolec 46(2):267-269. http://doi.org/10.1016/j.jibiomac.2009.11.003

34. Souza CÁPB, de Oliveira BA, Santos SAAR et al (2019) Orofacial antinociceptive effect of sulphated polysaccharide from the marine algae Hypnea pseudomusciformis in rodents. Inflammopharmacology 27:261-269. https://doi.org/10.1007/s10787-018-0454-4

35. Streck L, Sarmento VHV, Menezes RPRPB, Fernandes-Pedrosa MF, Martins AMC, Silva-Júnior AA (2018) Tailoring microstructural, drug release properties, and antichagasic efficacy of biocompatible oil-in-water benznidazol-loaded nanoemulsions. Int J Pharm 555:36-48. https://doi.org/10.1016/j.ijpharm.2018.11.041

36. Tiyboonchai W (2003) Chitosan nanoparticles: a promising system for drug delivery. Naresuan U J 11:3: $51-56$

37. Tsai HY, Chiu CC, Lin PC, Chen SH, Huang SJ, Wang LF (2011) Antitumor efficacy of doxorubicin released from crosslinked nanoparticulate chondroitin sulfate/chitosan polyelectrolyte complexes. Macromol Biosci 11:5:680-688. https://doi.org/10.1002/mabi.201000456

38. Youm I, Yang XY, Murowchick JB, Youan BBC (2011) Encapsulation of docetaxel in oily core polyester nanocapsules intended for breast cancer therapy. Nanoscale Res Lett 630:1-12. https://dx.doi.org/10.1186\%2F1556-276X-6-630

39. Zhou QQ, Imbe H, Dubner R, Ren K (1999) Persistent Fos protein expression after orofacial deep or cutaneous tissue inflammation in rats: implications for persistent orofacial pain. J Comp Neurol 412(19990920):276-291. https://doi.org/10.1002/(SICI)10969861. )412:2\%3C276::AIDCNE7\%3E3.0.CO;2-9

40. Zhou XH (1994) Overcoming enzymatic and absorption barriers to nonparenterally administered protein and peptide drugs. J Control Release 29:239-252. https://doi.org/10.1016/01683659(94)90071-X

\section{Figures}




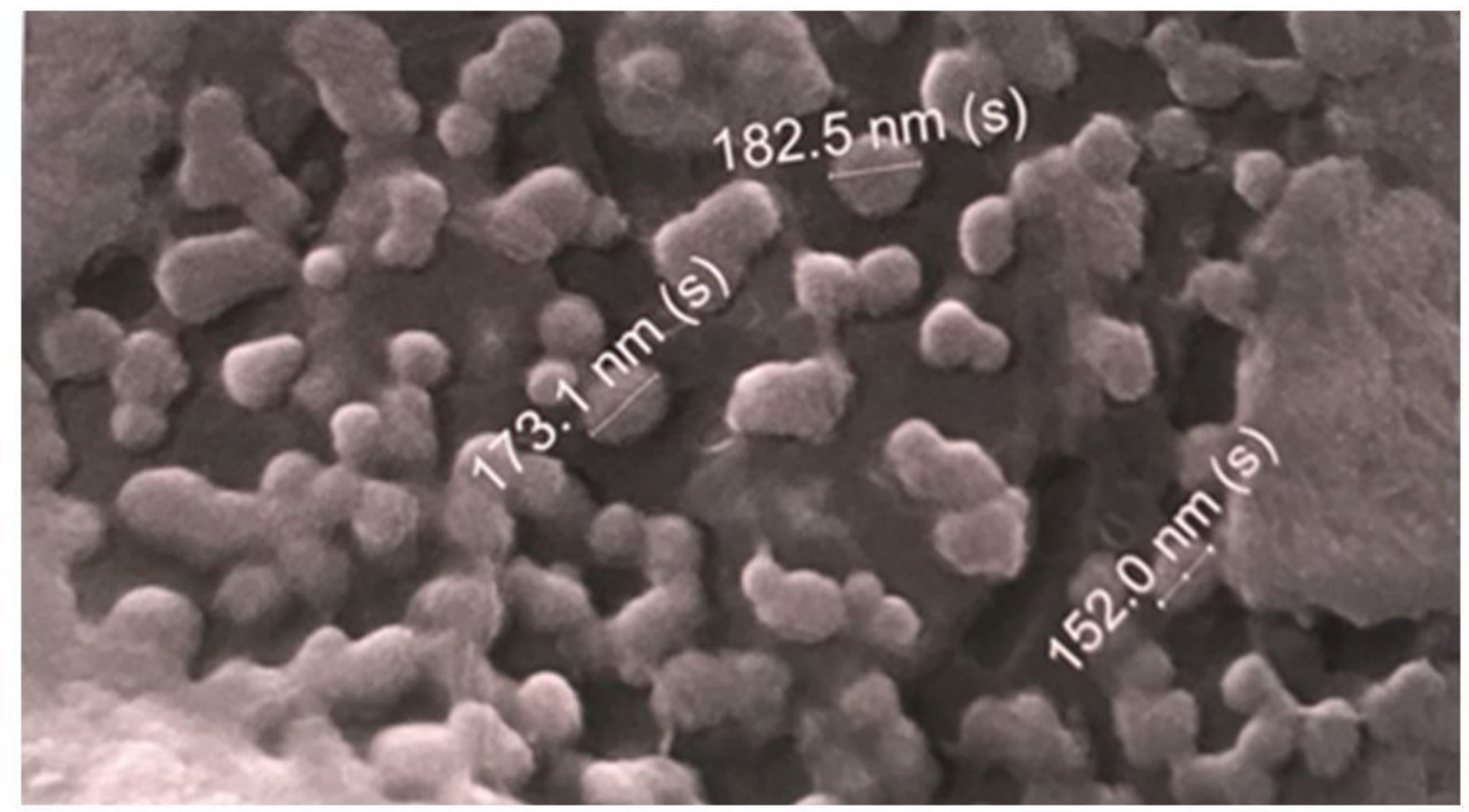

Figure 1

Scanning electron microscopy image of the chitosan nanocapsule containing FTL (1000 X) obtained by ionic gelification. 


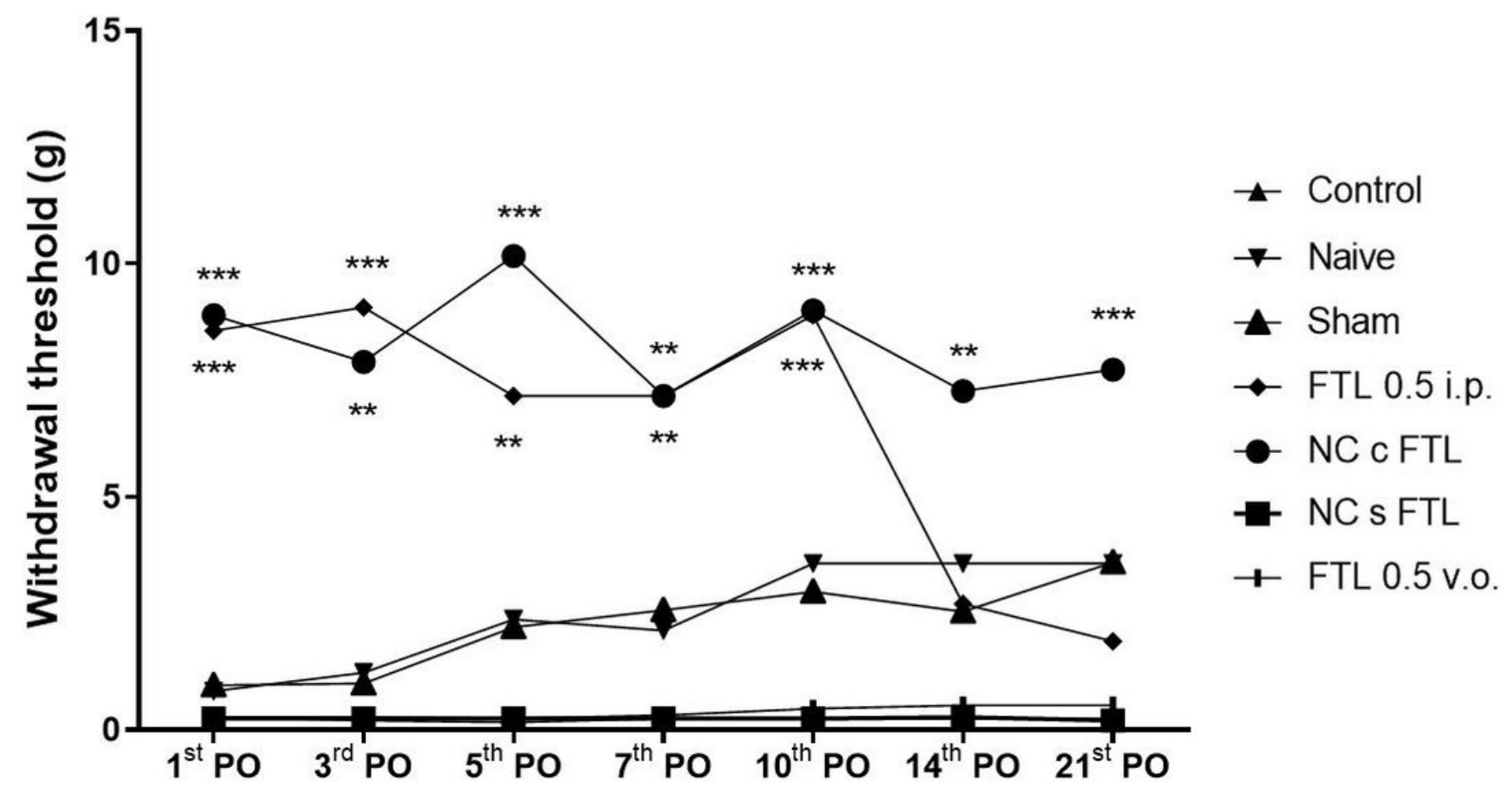

Figure 2

Effect of encapsulated and non-encapsulated frutalin (FTL) on mechanical hyperalgesia in animals submitted to infraorbital nerve transection. Data are expressed as mean \pm S.E.M. and compared to the control group. ${ }^{* \star} p<0.01$ and ${ }^{* \star \star} p<0.001$ vs. control. ANOVA followed by Bonferroni's test.

A

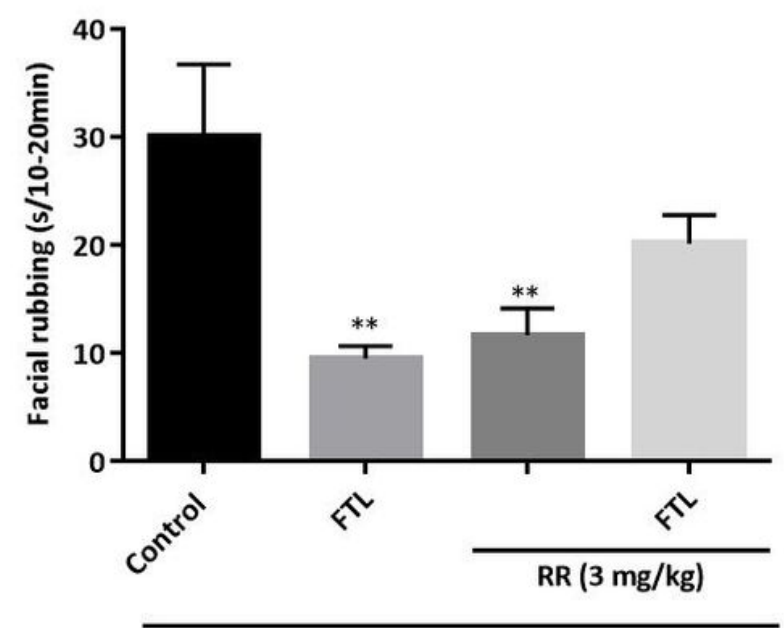

Capsaicin $(1.6 \mu \mathrm{g})$
B

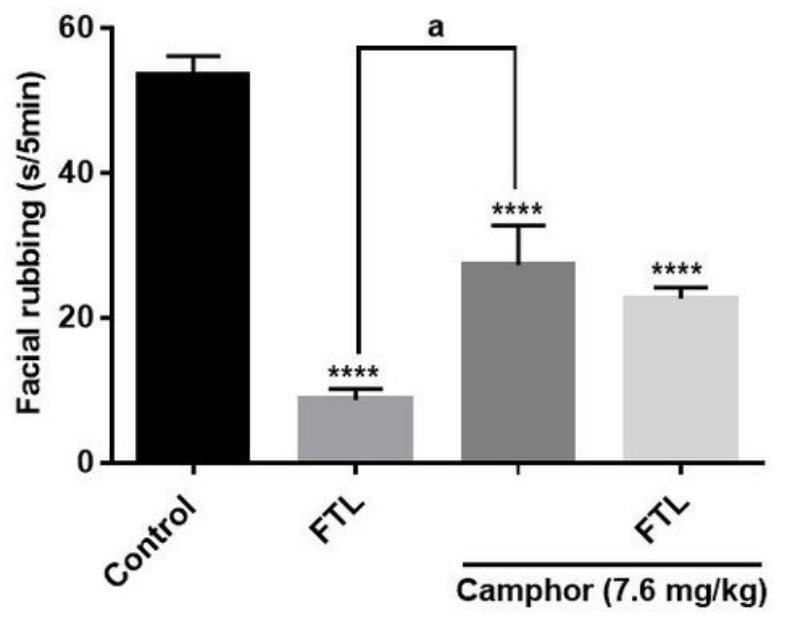

Cinnamaldehyde $(13.2 \mu \mathrm{g})$ 
Figure 3

Effect of frutalin (FTL) on orofacial nociception induced by capsaicin (A) and cinnamaldehyde $(B)$ in mice. Data are expressed as mean \pm S.E.M. and compared to control group. ${ }^{\star \star} p<0.01$ and ${ }^{\star \star \star} p<0.001$ vs. control; ${ }^{a} p<0.01$ vs. FTL. ANOVA followed by Tukey's test. RR = ruthenium red.

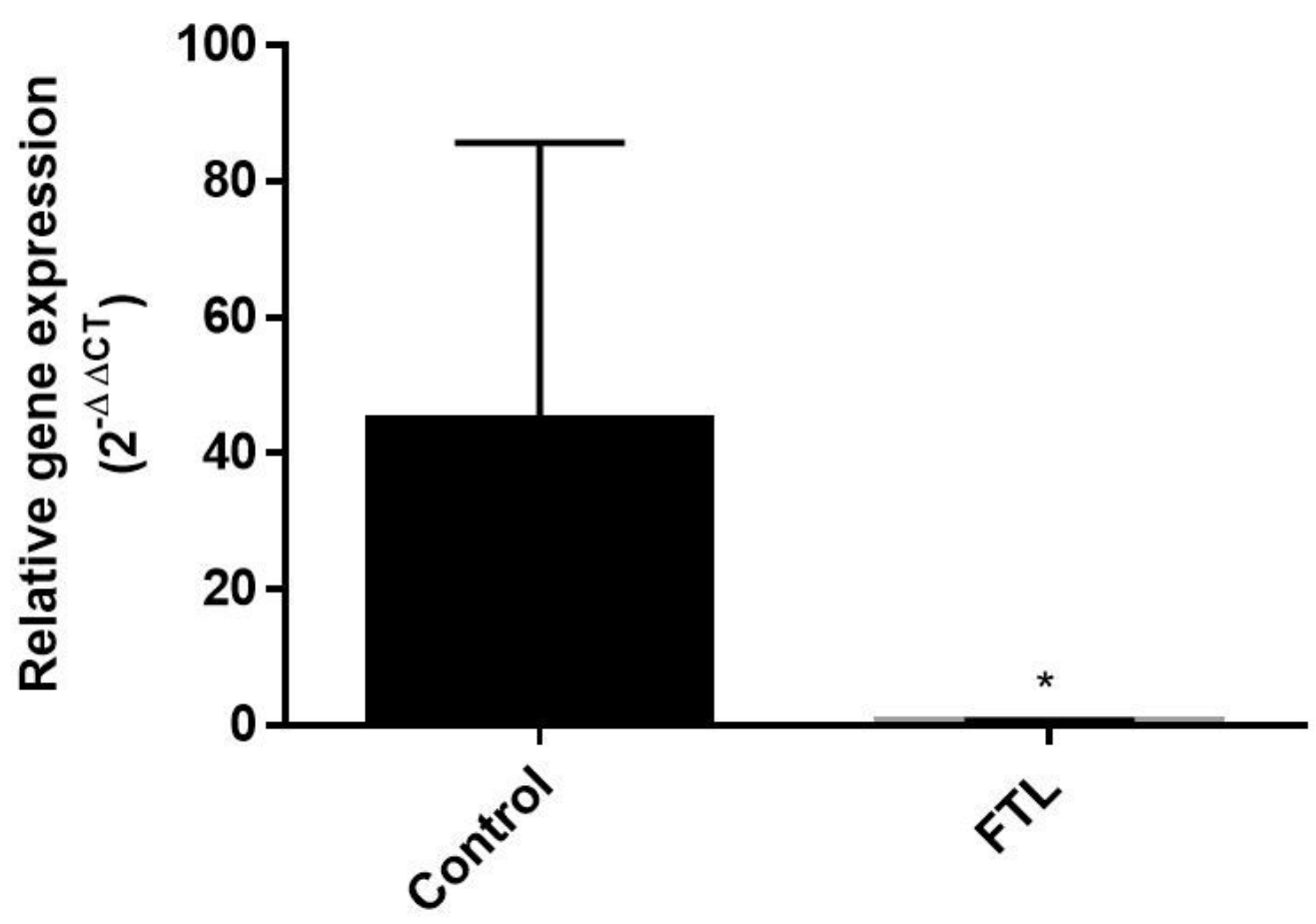

Figure 4

Trpv1 expression after nociceptive stimulus in mouse trigeminal ganglion is significantly reduced after Frutalin treatment. Trpv1 relative expression was evaluated and data normalized against Gapdh.

\section{Supplementary Files}

This is a list of supplementary files associated with this preprint. Click to download.

- Highlights1streviewfinal.doc 